\title{
PH Modeling of Neutralization Process in the Production of Soybean Protein Isolate
}

\author{
Yuxi Deng ${ }^{1}$, Hongmin Zhang ${ }^{1}$, Xiuhong Wang ${ }^{2}$ and Qingqiang Guo ${ }^{1, *}$ \\ ${ }^{1}$ School of Control Science and Engineering, Shandong University, Jinan 250061, China \\ ${ }^{2}$ Department of Electronic, Shandong College of Electronic Technology, Jinan 250061 China \\ *Corresponding author
}

\begin{abstract}
In the whole production process of soybean protein isolate, the neutralization section is a very important link, and the pH value is the most difficult to control in this section. The main reason is that the chemical reaction in the neutralization process has the characteristics of nonlinear, time delay and time-varying. The $\mathrm{pH}$ value will seriously affect the quality of the final protein isolate, so controlling the $\mathrm{pH}$ value of the neutralization section is particularly important. In this paper, we use laboratory equipment to simulate the neutralization process in the production of soybean protein isolate. In view of the characteristics of the neutralization process, the $\mathrm{pH}$ value model of the soy protein isolate is established. The particle swarm optimization algorithm is introduced to identify the parameters, and the identification results are identified with the recursive minimum two multiplication parameter identification and the genetic algorithm parameters. The results of comparison show that the parameter identification results of particle swarm optimization algorithm are obviously better than those of the other two algorithms.
\end{abstract}

Keywords-soybean protein isolate; $\mathrm{pH}$ model; particle swarm optimization

\section{INTRODUCTION}

Soybean protein isolate has high nutritional value and function, and its price is low. As a raw material and food additive, soy protein isolate has been widely used in the food industry ${ }^{[1]}$. The production process of soybean protein isolate requires strict control of the parameters of various production processes, and $\mathrm{pH}$ value is the main factor affecting the final protein.

Because of the nonlinear characteristics and complexity of the $\mathrm{pH}$ value control system, how to provide a good dynamic model of the $\mathrm{pH}$ neutralization process is an important direction that still continues to be studied ${ }^{[2]}$. The mathematical model of $\mathrm{pH}$ neutralization process was first proposed by McAvoy and Lowenthals ${ }^{[3]}$ in 1972. The model was based on mass conservation and mass ionization balance. The model was proved to be reasonable by test and it also laid the foundation for the study of subsequent $\mathrm{pH}$ neutralization process. In 1987 , Choi and Rhinehart ${ }^{[4]}$ proposed the concept of the total ion concentration in the reaction solution. The reaction solution was regarded as a single weak acid, and the two parameter model of the weak acid hydrolysis was obtained. The model had only two identification parameters and had a certain robustness and high rapidity. It could be approximated by a good approximation of the $\mathrm{pH}$ neutralization process.
In addition to the model based on chemical reaction, with the continuous improvement of nonlinear control theory and the continuous research of intelligent control, researchers began to use other nonlinear models to describe the process of $\mathrm{pH}$ neutralization based on the complex nonlinear and serious hysteresis of the $\mathrm{pH}$ neutralization process. GA Pajunen ${ }^{[5]}$ and J.L.Figueroa $^{[6]}$ use Wiener model to describe $\mathrm{pH}$ neutralization process. JC Gome $Z^{[7]}$ compares several common nonlinear identification methods with $\mathrm{pH}$ neutralization process in his paper. It points out that the Wiener model of support vector machine is of the highest precision, but it is generally not adopted because of its too many identification parameters. Eskinat $\mathrm{E}^{[8]}$ and others use the Hammerstein model to describe the $\mathrm{pH}$ neutralization process. The Hammerstein model is composed of two parts, dynamic linear and static nonlinear. The parameters are easy to identify, and many of them have been learned to describe the $\mathrm{pH}$ neutralization process. In a word, due to the nonlinearity and time-delay of $\mathrm{pH}$ neutralization process, it has been a hot research topic both at home and abroad.

The problems in modeling $\mathrm{pH}$ value of soybean protein isolate are mainly reflected in the following aspects: (1) the variation of inlet and outlet volume of soy protein isolate solution is unstable. The change of concentration of soy protein isolate solution will cause great disturbance to the system. (2) The components of soybean protein isolate are complex, which makes it difficult to determine the titration curve of the system. (3) Due to the mixing of neutralization tank and the actual measurement, transmission and control of the instrument, there are serious delay, noise and uncertainty in the whole process. To sum up, modeling based on modern nonlinear theory is relatively complex and requires a lot of data support. The soy protein solution isolate is a mixture, we do not know its specific components and concentrations. It is also difficult to establish a chemical reaction based on the chemical reaction. Therefore, the idea of ionizing the weak acid proposed by Choi and Rhinehart is introduced in this paper.

\section{LABORATORY SIMULATOR}

\section{A. Introduction to the Experimental Device}

In this paper, a bioreaction tank was used to simulate the neutralization process in the production of soybean protein isolate. 
Reaction tank with variable speed peristaltic pump is used to replace solenoid valve in the actual production process. The neutralization reaction of acid protein slurry and $\mathrm{NaOH}$ solution is added to the fermenting tank by the variable speed creep pump of the bio fermenting tank, and the neutralized slurry is extracted by the variable speed peristaltic pump. So we can keep neutralization tank volume to be fixed.

In the bioreactor, the reactor can make the neutralization reaction fully and quickly. The bioreactor also has the $\mathrm{pH}$ value sensor to detect the $\mathrm{pH}$ value of the slurry in the reaction tank. The acquisition frequency of the $\mathrm{pH}$ value of the reaction tank is 1 minutes, and the median filter is used to deal with the collected data.

The experimental device can simulate the continuous production of soybean protein isolate and neutralization section, and can reflect its process characteristics.

The overall structure of the experimental device is shown in figure I.

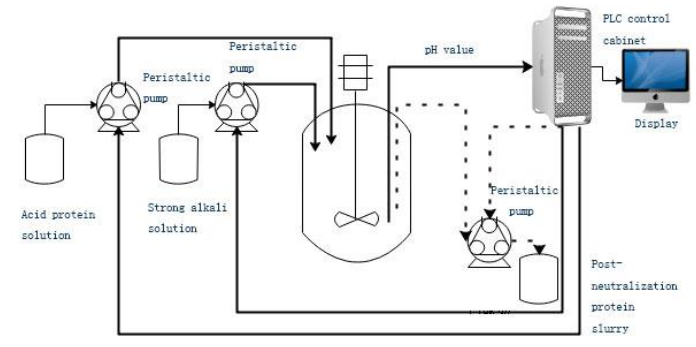

FIGURE I. THE STRUCTURE OF EXPERIMENTAL DEVICE.

\section{B. Experimental Design and Data Collection}

Before the experiment of the relationship between the peristaltic pump rotation speed and flow calibration, calibration using the measuring cylinder in the lab, let the peristaltic pump turn 4 minutes, traffic is $105 \mathrm{ml}$, so the average velocity of peristaltic pump is $26.25 \mathrm{ml} / \mathrm{min}$.

This experiment allows the acid protein slurry to enter the reaction tank at a constant flow rate, with an average flow rate of $26.25 \mathrm{ml} / \mathrm{min}$ (the rotational speed of the peristaltic pump is $18 \mathrm{rpm} / \mathrm{min}$ ), in order to ensure that the $\mathrm{pH}$ value in the tank is no more than 9 , so the sodium hydroxide ( $\mathrm{pH}$ value is 12.6$)$ is manually added to the flow rate of $26.25 \mathrm{ml} / \mathrm{min}$ (the peristaltic pump speed is $18 \mathrm{rpm} / \mathrm{min}$ ).

Experiment is divided into two groups, one group is mainly used to identify the unknown parameters of the $\mathrm{pH}$ value model of the neutralization reaction process of soybean protein isolate, a second set of experiments to verify the accuracy of the models.

The total duration of the first group was 5 hours. A stable period of data interception was selected. The sampling frequency of the controller was $1 \mathrm{~min}$, and 271 groups of data were collected.

The total duration of the second experiment was 1 hour, and 55 groups of data were also selected for a period of stable reaction.

\section{PH MODEL OF THE NEUTRALIZATION PROCESS}

The concept of $\mathrm{pH}$ was first proposed by the Danish biochemist Soren Peter Lauritz Sorensen in 1909. PH is defined as the negative logarithm of hydrogen ion concentration, expressed as formula (1):

$$
p H=-\log \left[H^{+}\right] \text {o }\left[H^{+}\right]=10^{-p H}
$$

$\left[\mathrm{H}^{+}\right]$is the concentration of hydrogen ions in solution, the unit is $\mathrm{mol} . \mathrm{L}^{-1}$.

Choi, based on the mechanism model of sewage treatment, proposed the concept of total ion concentration and single weak acid, that is, to think of the acid sewage to be treated as an unknown weak acid, to identify the concentration and ionization constant of hypothetical acid online. In the treatment of the sewage mechanism model, the effect of the addition of strong alkali solution on the total volume of the solution was not considered.

Due to the large amount of alkali added in neutralization section, the total volume of solution cannot be neglected. Therefore, according to the idea of single weak acid ionization, the soy protein isolate solution is regarded as a single virtual acid and an unknown dissociation constant of unknown concentration, and the effect of strong alkali solution on the total volume is taken into account.

Assuming that soy protein isolate solution is a single virtual weak acid, the ionization equilibrium equation of each component in the continuous reaction kettle during the neutralization process of soy protein isolate is shown in table 1.

TABLE I. IONIZATION EQUILIBRIUM EQUATION OF EACH COMPONENT IN A NEUTRALIZING TANK

\begin{tabular}{|c|c|}
\hline $\begin{array}{c}\text { The initial } \\
\text { concentration }\end{array}$ & The reaction \\
\hline$C_{1}$ & $\left(C_{1}-x\right) H B \stackrel{K a}{\longrightarrow} x H^{+}+x B^{-}$ \\
\hline$c$ & $\mathrm{NaOH} \rightarrow c \mathrm{Na}^{+}+c \mathrm{OH}^{-}$ \\
\hline
\end{tabular}

The equation of hydro-electric separation is shown in equation (2):

$$
\mathrm{H}_{2} \mathrm{O} \stackrel{K_{w}}{\longrightarrow} \delta H^{+}+\delta O H^{-}
$$

In table I, $C_{1}$ represents the initial concentration of virtual acid, $\mathrm{X}$ represents the concentration of $B^{-}$after Ionization balance, $\delta$ represents the concentration of $H^{+}$which is ionized by water. $\varepsilon$ represents the concentration of $\mathrm{NaOH}$ in the solution, $K_{a}$ represents the ionization equilibrium constant of the virtual acid, and $K_{w}$ represents the ionic product of water, $K_{w}=\left[\mathrm{H}^{+}\right]\left[\mathrm{OH}^{-}\right]$.

According to the definition of ionization equilibrium constant, formula (3) can be obtained: 
Formula (4) and formula (5) can be defined by the ionproduct formula of water and $\mathrm{pH}$ value and Table I:

$$
\begin{gathered}
K_{a}=\frac{\left[H^{+}\right]\left[B^{-}\right]}{[H B]}=\frac{(x+\delta)(x)}{\left(C_{1}-x\right)} \\
K_{w}=\left[H^{+}\right]\left[O H^{-}\right]=(x+\delta)(\delta+c) \\
P H=-\log _{10}{ }^{\left[H^{+}\right]}=-\log _{10}(x+\delta)
\end{gathered}
$$

Formula (6) can be obtained from (3), (4) and (5):

$$
K_{a}-\frac{10^{-P H}\left(10^{-P H}-K_{w} \times 10^{P H}+c\right)}{\left(C_{1}-10^{-P H}+K_{w} \times 10^{P H}-c\right)}=0
$$

It is assumed that the volume of the continuous reactor is $\mathrm{V}$, the initial concentration of sodium hydroxide is $c_{0}$, the flow rate of the acid protein solution is $F_{a}(\mathrm{ml} / \mathrm{min})$, the flow rate of sodium hydroxide is $F_{b}(\mathrm{ml} / \mathrm{min})$, and $c$ can be obtained according to the mass conservation theorem, and the formula (7) is expressed as follows:

$$
V \frac{d c}{d t}=F_{b} c_{0}-\left(F_{a}+F_{b}\right) c
$$

According to equation (7), there are only two unknown parameters of equation (6), $C_{1}$ and $K_{a}$, and equations (6) and (7) constitute a two-parameter model of the neutralization process of soybean protein isolate.

It can be seen that the single acid two-parameter model can greatly reduce the identification parameters of the model, simplify the model, and reflect the characteristics of the multicomponent neutralization reaction.

Since this model has only two parameters to be identified, it has high flexibility.

This model also has certain limitations. It is difficult to completely fit the titration curve of system components under the condition of high or low $\mathrm{pH}$ value.

Soy protein isolate solution $\mathrm{pH}$ value is between $4.5 \sim 8.5$, if we can choose $C_{1}$ and $K_{a}$ reasonably and make the model match the process curve in section 4.5 8.5, the double parameter model can well simulate the neutralization process in the production of soybean protein isolate, so this paper adopts double parameter model to identify the neutralization process in the production of soybean protein isolate.

\section{MODEL PARAMETER IDENTIFICATION AND MODEL VERIFICATION}

After the establishment of mathematical model of the neutralization process in the production of soybean protein isolate, it is very important to evaluate the model to ensure that the model can reflect the dynamic characteristics of the actual neutralization process. Murray Smith ${ }^{[9]}$ mentioned the problem of model precision and verification of control system design in his related paper. Murray Smith also suggests methods for model validation that demonstrate the closeness of the development model to the actual system. One of the methods mentioned provides more quantitative information than the graphical comparison method, Theil's Inequality Coefficient (TIC). As suggested by Murray Smith in his paper, the TIC value less than 0.3 usually makes the developed model consistent with the actual transient, enough to be applied to the design of the control system. Therefore, this paper uses TIC value to evaluate whether the built model can reflect the actual system.

The least-square estimation method is widely used in system identification and parameter estimation, but when the calculated matrix dimension increases, the calculation amount will increase sharply, which is not suitable for online parameter identification $^{[10]}$. In order to reduce the calculation amount, the recursive least square method can be adopted. The parameter estimation of the new moment is recursive from the estimate of the previous moment, which reduces the calculation amount. With the development of optimization theory, some intelligent algorithms have been applied to solve the problems of system identification, such as genetic algorithm and particle swarm optimization algorithm.

Particle swarm optimization (PSO) is a random search algorithm based on group collaboration. It has many similarities with genetic algorithm, but it is simpler than genetic algorithm. The algorithm is easy to implement and has high precision and fast convergence. It usually outperforms genetic algorithm in solving practical problems.

Based on recursive least square method, genetic algorithm and particle swarm optimization algorithm, the results of twoparameter model parameter identification of soybean protein neutralization process are shown in table II.

TABLE II. PARAMETER IDENTIFICATION RESULTS OF THREE DIFFERENT ALGORITHMS.

\begin{tabular}{|c|c|c|c|}
\hline The Parameter Name & $C_{1}$ & $K_{a}$ & TIC \\
\hline Recursive least squares & 0.005916 & 6.6352 & 0.2140 \\
\hline Genetic algorithm (GA) & 0.005612 & 6.5561 & 0.1621 \\
\hline $\begin{array}{c}\text { Particle swarm } \\
\text { optimization algorithm }\end{array}$ & 0.005603 & 6.5201 & 0.0918 \\
\hline
\end{tabular}




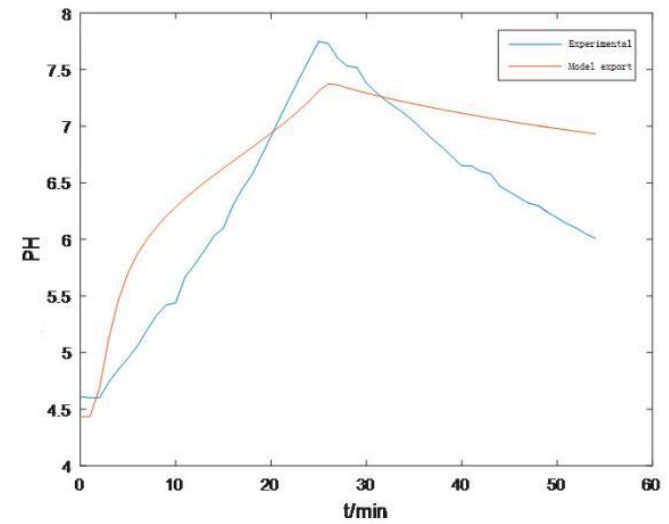

FIGURE II. RESULTS OF RECURSIVE LEAST SQUARE PARAMETER IDENTIFICATION.

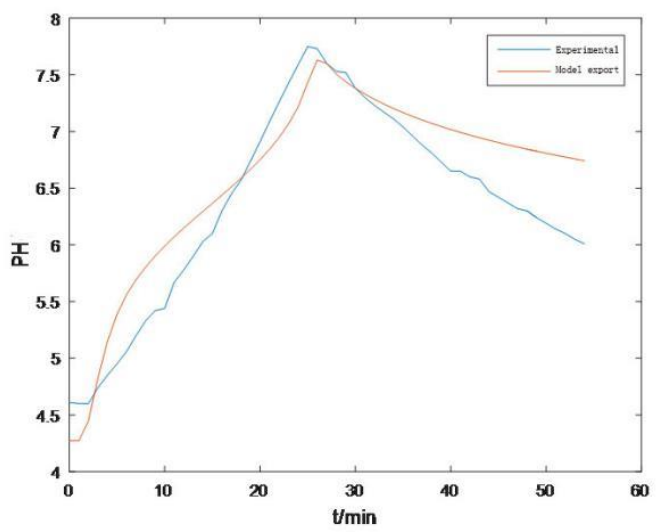

FIGURE III. RESULTS OF PARAMETER IDENTIFICATION OF GENETIC ALGORITHM.

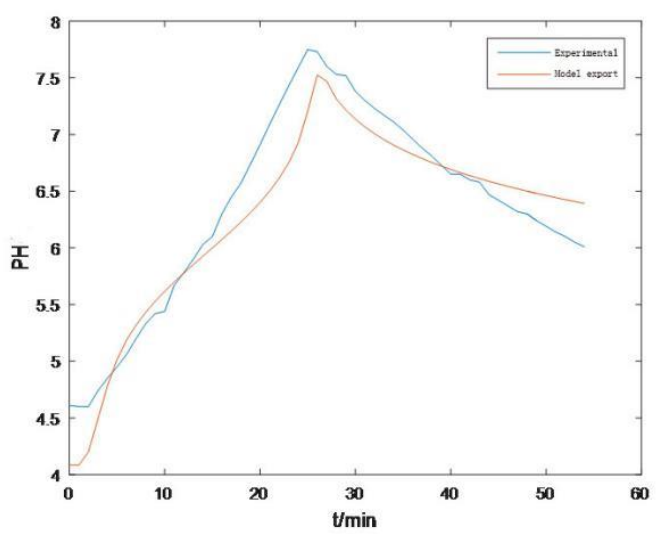

FIGURE IV. PARAMETER IDENTIFICATION RESULTS OF PARTICLE SWARM OPTIMIZATION ALGORITHM.

From the perspective of TIC value, the parameter identification results of particle swarm optimization algorithm are better than those of recursive least-squares algorithm and genetic algorithm, and the identification results are more consistent with the actual system.

\section{CONCLUSION}

According to the process characteristics of the neutralization process in the production of soybean protein isolate, an experimental device was set up to simulate the process of soybean protein neutralization. In this paper, a twoparameter model of $\mathrm{pH}$ value of neutralization section is established by introducing the idea of single weak acid ionization and taking into account the influence of strong alkali solution on the total product of solution. For the unknown parameters in the model, the particle swarm optimization algorithm is used to identify the parameters. It is proved that the mathematical model of neutralization process can reflect the actual dynamic characteristics of the $\mathrm{pH}$ value of the soy protein isolate and the section.

\section{ACKNOWLEDGMENT}

Financial support for this work was provided by the Key Research and Development Program of Shandong Provence (No.2016ZDJS02B02).

\section{REFERENCES}

[1] Zhao JY Dong FJ, LiY Y Kong BH, Liu Q. Effect of freeze--thaw cycles on the emulsion activity and structural characteristics of soy protein isolate. Process Biochemistry, 2015.50(10): 1607-1613.

[2] R. Ibrahim.Practical, Modelling And Control Implementation Studies On A pH Neutralization Process Pilot Plant[D].PhD Thesis, 2008.

[3] McAvoy, T. J., Hsu, E., Lowenthals, S., Dynamics of pH in controlled stirred tank reactor[J]. Industrial \& Engineering Chemistry Process Design \& Development, 1972,11(1):68-78.

[4] JY Choi ,RR Rhinehart.Internal Adaptive-Model Control of Wastewater pH[C]. American Control Conference, 1987 :2084-2089.

[5] GA Pajunen, Identification and Adaptive Control of Wiener Type Nonlinear Processes[J]. IFAC Proceedings Volumes, 1985,18 (11): 493500 .

[6] J.L.Figueroa,J.E. Cousseau,S.Werner,T.Laakso ,Adaptive control of a Wiener type system: application of a $\mathrm{pH}$ Neutralization reactor [J]. International Journal of Control, 2007, 80 (2):231-240.

[7] JC Gomez. Comparison of nonlinear identification techniques on a benchmark $\mathrm{pH}$ neutralization process[C]. Electrical, Electronics Engineering, Information \& Communication Technologies, 2016: 153158.

[8] E Eskinat,SH Johnson,WL Luyben,Use of Hammerstein models in identification of nonlinear systems [J]. Aiche Journal, 1991,37(2): 255268.

[9] Murray-Smith, D. J., Methods for the external validation of continuous system simulation models: A review[J]. Mathematical and Computer Modelling of Dynamical Systems, 1998,4(1):5-31.

[10] Lawryncruk,M.On-line Set-Point optimization and predictive control using neural hammer-stein models[J]. Chemical Engineering Journal. 2011, 166(1): 269-287. 